\title{
Spina bifidalı çocukların yaşam kalitesi üzerine temiz aralıklı kateterizasyonun etkisi
}

\author{
The effects of clean intermittent catheterisation use on quality of life of children with \\ spina bifida
}

\author{
Abdullah Erdem Arıkan, Cengiz Candan
}

Gönderilme tarihi:27.04.2020

Kabul tarihi:24.05.2020

\begin{abstract}
Özet
Amaç: Bu çalışmanın amacı, spina bifidalı çocuk ve ergenlerin yaşam kalitesi üzerine üriner inkontinans ve temiz aralıklı kateterizasyonun etkilerini değerlendirmektir.

Gereç ve yöntem: Spina bifida tanılı 7-17 yaş aralığındaki 98 hasta (52 erkek) çalışmaya katıldı. Hastaların yaş, kontinans ve hastalığa özgü verileri tıbbi kayıtlarından elde edildi. Hastalar üç yaş grubuna ayrıldılar; Grup 1: 6-7 yaş, Grup 2: 8-12 yaş ve Grup 3: 13-17 yaş. Katılan hastalardan KINDL-R genel yaşam kalitesi ölçeği ile birlikte spina bifida modülünü de doldurmaları istendi.

Bulgular: Yetmiş dokuz çocuk temiz aralıklı kateterizasyon yapıyordu. Temiz aralıkı kateterizasyon uygulayan ergenlerde (grup 3) genel hayat kalitesinin fiziksel iyilik, emosyonel iyilik, özsaygı ve hastalık algısı alt boyutlarında temiz aralıklı kateterizasyon yapmayan ergenler ile karşılaştırıldığında daha düşük skorlar bulundu. Temiz aralıklı kateterizasyon uygulayan ve uygulamayan diğer yaş gruplarındaki çocuklar arasında ise hiç bir alt grup için anlamlı fark yoktu. Ayrıca spina bifida modülüne göre temiz aralıklı kateterizasyon uygulayan ve uygulamayan gruplar arasında da anlamlı fark saptandı.

Sonuç: Bizim bulgularımıza göre daha küçük çocuklarda kontinans durumunun yaşam kalitesi üzerine etkili olmamasına karşın ergenlerdeki farklılık bu yaş grubunda baskın hale gelen sosyal hayat algısında gelişme ile ilişkili olabilir. Ayrıca spina bifida modülü ile ortaya konan aşikar fark bu hastalık grubunun değerlendirilmesinde hastalığa özgün anketlerin kullanımasını görüşünü destekler.
\end{abstract}

Anahtar kelimeler: Spina bifida, inkontinans, yaşam kalitesi, çocuklar.

Arıkan AE, Candan C. Spina bifidalı çocukların yaşam kalitesi üzerine temiz aralıklı kateterizasyonun etkisi. Pam Tıp Derg 2020;13:561-567.

\begin{abstract}
Purpose: The purpose of the study was to assess the effect of bladder incontinence and the practise of clean intermittent catheterisation on the quality of life of children and adolescents with spina bifida.

Materials and methods: Ninety-eight children (52 males) with spina bifida between 7 and 17 years were enrolled in the study. Data on continence, child age, and condition-specific variables were obtained by chart review. Pediatric spina bifida patients were divided into three age groups: Group 1: 6-7 years, Group 2: 8-12 years, and Group 3: 13-17 years. Participating children were asked to fill out the validated KINDL-R questionnaire, combined with specific spina bifida questions.

Results: Seventy-nine patients were using clean intermittent catheterization. Adolescents who performed clean intermittent catheterization (group 3) were found to have lower scores in several domains of general quality of life including physical wellbeing, emotional wellbeing, self-esteem and disease perception in comparison to those of adolescents who did not. None of the domains significantly differed in other age groups between children undergoing clean intermittant cathetherization and those who did not. There was also significantly difference between total quality of life scores of the group performing clean intermittent catheterization and the group not performing clean intermittent catheterization according to KINDL-spina bifida module.

Conclusion: According to our findings, while quality of life may not be affected by continence status among young children with spina bifida, the difference in adolescents may be related to the development of social life perception and emotional factors that become prominent in adolescents. However, the apparent difference with the spina bifida module supports the use of disease-specific questionnaires for the evaluation of factors in this patient group.
\end{abstract}

Key words: Spina bifida, incontinence, quality of life, children.

Arikan AE, Candan $\mathrm{C}$. The effects of clean intermittent catheterisation use on quality of life of children with spina bifida. Pam Med J 2020;13:561-567.

Abdullah Erdem Arıkan, Uzm. Dr. İstanbul Medeniyet Üniversitesi Tıp Fakültesi, Göztepe Eğitim ve Araştırma Hastanesi, Çocuk Sağlığı ve Hastalıkları Anabilim Dalı, İstanbul, Türkiye, e-posta: 88.erdem@gmail.com (orcid.org/0000-0002-6686-5870)

Cengiz Candan, Doç. Dr. İstanbul Medeniyet Üniversitesi Tıp Fakültesi, Göztepe Eğitim ve Araştırma Hastanesi, Çocuk Sağlığı ve Hastalıkları Anabilim Dalı, İstanbul, Türkiye, e-posta: cengizcandan@hotmail.com (orcid.org/0000-0002-9560-8304) (Sorumlu Yazar) 


\section{Giriş}

Spina bifida, embriyolojik dönemde omuriliğin gelişimi sırasında nöral tüpün tam olarak kapanmaması sonucu oluşan bir merkezi sinir sistemi anomalisidir. Dünya genelinde insidansı 1000 canlı doğumda yaklaşık 1 olarak bildirilmekle birlikte etnik ve coğrafi farklılıklar görülmektedir. Geçmişte oldukça yüksek mortalite ve morbidite oranları varken cerrahi ve tıbbi tedavi yöntemlerindeki gelişmeler hastaların sağkalım oranlarını ciddi ölçüde iyileştirmiştir [1].

Sağ kalım oranlarının ve yaşam süresinin artmasıyla birlikte spina bifida'lı hastaların yaşam kalitesine verilen önem artmıştır. Spina bifida'lı çocuklarda lökomotor ve duysal kusurların yanısıra, bağırsak ve mesane kontrol bozuklukları da günlük aktivitelerde önemli oranlarda kısıtııı̆a yol açar ve hastaların yaşam kalitesini olumsuz yönde etkiler [2, 3]. Hastaların günlük yaşam aktivitelerini gerçekleştirebilmeleri, rehabilitasyon programının düzenlenmesi ve tedavi yanıtının değerlendirilmesi açısından çok önemlidir. Spina bifida'lı çocuklar ve ergenler, diğer kronik hastalığı olan çocuklara göre de daha düşük bir yaşam kalitesine sahiptir. Ancak bu çocuklarda işlevsel durumu ve sağlık ile ilgili yaşam kalitesini değerlendirmek için geliştirilmiş sınırlı sayıda yöntem ve çalışma vardır. Değişik yöntemler ile yapılan çalışmaların sonuçları da oldukça çelişkilidir [1, 4].

$\mathrm{Bu}$ çalışmada, mesane kontrolünün sıklıkla bozulduğu spina bifida'lı hastalarda inkontinansın olumsuz etkilerini azaltmak için uygulanan temiz aralıklı kateterizasyon (TAK) işleminin hastaların yaşam kalitesi üzerine etkisinin araştırılması amaçlanmıştır.

\section{Gereç ve yöntem}

\section{Hasta seçimi}

İstanbul Medeniyet Üniversitesi Göztepe Eğitim ve Araştırma Hastanesi Çocuk Nefroloji Polikliniği'nde izlenen ve Ocak-Aralık 2018 tarihleri arasında poliklinik izlemine gelen spina bifida tanılı hastalardan; 6-18 yaş arasında okuma-yazma bilen, anket sorularını anlayıp cevaplayabilecek yeterlilikte olan ve çalışmaya katılmayı kabul eden 98 hasta çalışma grubu olarak seçildi. Hasta ve ailelerine ayrıntılı bilgi verildikten sonra sakin ve sessiz bir ortamda yeterli süre sağlanarak anketin tamamlanması sağlandı. Kognitif işlev bozukluğu olan hastalar ile yakın zamanda cerrahi girişim geçiren ve ek hastalıkları olan çocuklar çalışma dışı bırakıldı.

\section{2. Çocuklarda yaşam kalitesi ölçeği (KINDL-R)}

Çocuklarda yaşam kalitesi ölçeğinin [Çocuklar için Genel Amaçlı Sağlıkla İlgili Yaşam Kalitesi Ölçeği, "KINDer Lebensqualitätsfragebogen, Children Quality of Life-Questionnaire" (KIND)], bedensel iyilik, duygusal iyilik, öz saygı, aile, arkadaş ve okul olmak üzere altı boyutu vardır. Her bir boyut 4 maddeden oluşmaktadır. Boyutlara ait puanlar bağımsız olarak hesaplanırken ayrıca bu altı boyutun bileşiminden oluşan toplam yaşam kalitesi puanı da elde edilmektedir. Maddelere verilen puanlar 1'den (asla) 5'e (daima) doğru sıralanmış Likert tipi ölçüm ile ölçeklendirilmiştir. Sorunun yazım biçimine göre olumsuz yönelimli maddeler tersine çevrilerek puanlanmıştır. Ayrıca her bir boyut için maddelere verilen puanların sayılması, $\quad 0-100$ arasında ölçeklendirilecek şekilde dönüştürülmesi ve özetlenmesi ile puan hesabı yapılır. Çocuklarda yaşam kalitesi ölçeğinin farklı yaş grupları için düzenlenmiş üç sürümü vardır. Bunlar: 4-7 yaş çocuklar için Kiddy-KINDL (görüşmeci aracılığıyla yanıtların çocuktan alındığı sürüm), 8-12 yaş çocuklar için Kid-KINDL ve 13-16 yaş ergenler için Kiddo-KINDL'dır. Anket sorularının hepsi çocuklar tarafından doldurulmuştur. Daha önce yapılan çalışmalarda Türkçe KINDL'ın yaşam kalitesi ölçümünde geçerli ve güvenilir olduğu gösterilmiştir [5].

\section{KINDL-R spina bifida modülü (7-17 yaş)}

Spina bifida hastalarına özel olarak oluşturulmuş 37 sorudan oluşan ayrı bir KINDL-R yaşam ölçeğidir. İlk 29 soru hastanın yaşam kalitesini değerlendiren sorulardan oluşmakta olup 1'den 5'e (hiç:1, nadiren:2, bazen:3, çoğu zaman:4, her zaman:5) doğru sıralanmış Likert tipi ölçüm ile ölçeklendirilmiştir. 30. ve 31. sorular hasta alt bezi kullanımı, 32. soru TAK uygulanması ile ilgili, son 5 soru ise hastanın doktoru ile ilgili görüşlerini bildirdiği sorulardan oluşmaktadır. Henüz Türkçe için geçerlilik ve güvenilirlik testleri tamamlanmamakla birlikte ön çalışmalar mevcuttur [6]. 


\section{Bilgilendirilmiş onam ve etik kurul onayı}

Çalışmamızda yer alan hastalar ve ailelerine çalışma hakkında bilgi verilerek onam alındı. Çalışma Helsinki Deklerasyonu'na uygun olarak yürütülmüş ve çalışma hakkında bilgi verilerek onam alındı. Çalışma Helsinki Deklerasyonu'na uygun olarak İstanbul Medeniyet Üniversitesi Göztepe Eğitim ve Araştırma Hastanesi Klinik Araştırmalar Etik Kurulu'nun 12.12.2018 tarih ve 2018/0490 sayılı etik kurul onayı gözetilmiştir.

\section{5. İstatistiksel çözümleme}

Çalışmanın tüm istatistiksel analizleri SPSS 24 (Statistical Package for Social Science, version 24) kullanılarak yapılmıştır. Değişkenlerin normal dağılıma uygunluğu histogram grafikleri ve Kolmogorov-Smirnov testi ile incelendi. Tanımlayıcı analizler sunulurken ortalama, standart sapma, ortanca ve minimummaksimum değerler kullanılmıştır. Kategorik değişkenlerin analizi $\mathrm{Ki}$ kare bağımsızlık testi ile gerçekleştirilmiştir. Normal dağııım göstermeyen (nonparametrik) değişkenler iki grup arasında değerlendirilirken Mann Whitney $U$ Testi kullanılmıştır. $P$ değerinin 0,05 'in altında olduğu durumlar istatistiksel olarak anlamlı sonuçlar şeklinde değerlendirildi.

\section{Bulgular}

\section{Hastaların demografik ve klinik özellikleri}

Çalışmaya yaşları 6-18 yaş arası olan $46 \mathrm{kız}$ ve 52 erkek olmak üzere toplam 98 spina bifida tanılı hasta katılmıştır. Hastaların demografik ve bazı klinik özellikleri Tablo 1'de özetlenmiştir. Temiz aralıklı kateterizasyon uygulaması ve alt bezi kullanımı açısından kız ve erkek hastalar arasında istatistiksel olarak anlamlı bir fark yoktur $(p>0,05)$.

Temiz aralıkı kateterizasyon uygulanması ile yaşam kalitesi ölçeği arasındaki ilişki iki ayrı KINDL-R modülü uygulanarak incelenmiştir.
Bunlardan birincisi KINDL-R genel yaşam kalitesi ölçeği, ikincisi ise spina bifida hastalarına özel oluşturulmuş KINDL-R yaşam kalitesi ölçeğidir.

\section{KINDL-R genel yaşam kalitesi ölçeği sonuçları}

Yaş gruplarına göre KINDL-R genel yaşam kalitesi ölçeğinde TAK uygulanması ile yaşam kalitesi arasındaki ilişki yaş gruplarına göre 3 kategoride incelenmiştir. On üç yaş ve üzeri grubun sonuçları Tablo 2'de verilmiştir. Buna göre TAK uygulayan ergenlerde KINDL-R genel yaşam kalitesi ölçeğinin 6 alt boyutundan bedensel iyilik hali, duygusal iyilik hali ve özsaygı alt boyutları ile hastalık algısı ölçeklerinde puanların TAK uygulamayan hastalara göre istatistiksel olarak daha düşük olduğu saptanmıştır (Tablo 2).

Bununla birlikte KINDL-R genel yaşam kalitesi ölçeğinde herhangi bir alt boyut için 4-7 yaş arası ve 8-12 yaş arası çocukların yaşam kalitesinde TAK uygulamasına bağlı istatistiksel olarak herhangi anlamlı bir fark saptanmamıştır (veriler gösterilmemiştir).

\section{KINDL-R spina bifida modülü sonuçları}

Tüm yaş gruplarına uygulanan spina bifida hastalarına özel olarak hazırlanmış KINDL-R spina bifida modülünde TAK uygulayan hastalar ile uygulamayan hastaların yaşam kalitesi karşılaştırıımıştır. Hastaların yaşam kalitesi anketine verdikleri yanıtlar ve TAK uygulama durumuna göre ayrıntılı incelenmesi Tablo 3'de görülmektedir. Bunlar arasında 12 tekil maddede TAK yapan ve yapmayan hastalar arasında istatistiksel olarak anlamlı fark saptanmıştır. Temiz aralıklı kateterizasyon uygulayan hastaların genel ortalama değeri de TAK uygulamayan hastalardan anlamlı derecede farklı bulunmuştur $(p=0,012)$. 
Tablo 1. Hastaların demografik ve klinik özellikleri

\begin{tabular}{ll}
\hline Parametre & $\mathbf{n ~ ( \% )}$ \\
\hline Cinsiyet, Kız/Erkek, & $46(47) / 52(53)$ \\
Yaş, yıl & $11,79 \pm 3,46$ \\
$\quad 6-7$ yaş & $13(\% 13,3)$ \\
$\quad$ 8-12 yaş, & $40(\% 40,8)$ \\
$\quad>13$ yaş, & $45(\% 45,9)$ \\
Lezyon seviyesi & \\
$\quad$ Lomber, & $58(\% 59,2)$ \\
$\quad$ Lumbosakral & $19(\% 19,4)$ \\
$\quad$ Sakral, & $21(\% 21,4)$ \\
Yürüyebilme & $41(\% 42)$ \\
Temiz aralıklı kateterizasyon, n (\%) & $79(\% 80,6)$ \\
Alt bezi kullanımı, & $64(\% 65,3)$ \\
\hline
\end{tabular}

Tablo 2. KINDL-R genel yaşam kalitesi ölçeğinde 13 yaş ve üzeri çocuklarda temiz aralıklı kateterizasyon uygulaması ile yaşam kalitesi arasındaki ilişki

\begin{tabular}{|c|c|c|c|c|c|}
\hline \multirow[t]{2}{*}{ Skala (madde sayısı) } & \multicolumn{2}{|c|}{$\begin{array}{l}\text { TAK yapan hastalar } \\
(\mathrm{n}: 36)\end{array}$} & \multicolumn{2}{|c|}{ TAK yapmayan hastalar $(n: 9)$} & \multirow[t]{2}{*}{$p^{*}$} \\
\hline & Ortalama \pm SD & $100^{\prime}$ lük skala & Ortalama $\pm S D$ & $100^{\prime}$ lük skala & \\
\hline $\begin{array}{l}\text { Bedensel İyilik Hali } \\
\text { (4) }\end{array}$ & $3,5 \pm 0,6$ & $63,6 \pm 13,9$ & $4,2 \pm 0,9$ & $80,0 \pm 22,8$ & 0.012 \\
\hline $\begin{array}{l}\text { Duygusal İyilik Hali } \\
\text { (4) }\end{array}$ & $3,8 \pm 0,4$ & $70,0 \pm 9,7$ & $4,5 \pm 0,7$ & $81,3 \pm 16,1$ & 0,009 \\
\hline Özsaygı (4) & $3,0 \pm 0,5$ & $50,7 \pm 11,9$ & $3,7 \pm 80$ & $68,1 \pm 20,9$ & 0,007 \\
\hline Aile (4) & $4,1 \pm 0,5$ & $77,7 \pm 12,5$ & $4,6 \pm 0,9$ & $81,3 \pm 22,6$ & 0,176 \\
\hline Arkadaş (4) & $3,3 \pm 0,5$ & $57,5 \pm 12,5$ & $3,9 \pm 1,0$ & $72,5 \pm 25,9$ & 0,182 \\
\hline Okul (4) & $3,5 \pm 0,4$ & $63,2 \pm 10,9$ & $3,9 \pm 0,9$ & $72,5 \pm 21,5$ & 0,166 \\
\hline Hastalık algısı (6) & $3,5 \pm 0,4$ & $63,2 \pm 10,1$ & $4,1 \pm 0,8$ & $77,1 \pm 20,3$ & 0,026 \\
\hline Total (30) & $3,6 \pm 0,4$ & $63,8 \pm 8,9$ & $4,0 \pm 0,8$ & $75,9 \pm 20,2$ & 0,059 \\
\hline
\end{tabular}


Tablo 3. KINDL-R Spina bifida modülüne göre temiz aralıklı kateterizasyon uygulamasının yaşam kalitesi üzerine etkileri

\begin{tabular}{|c|c|c|c|}
\hline Maddeler & $\begin{array}{l}\text { TAK }(+) \\
\mathrm{n}=79\end{array}$ & $\begin{array}{l}\text { TAK (-) } \\
\mathrm{n}=19\end{array}$ & $p$ \\
\hline 1. Okul ya da mahalleden arkadaşlarım beni misafirliğe çağırır & $3,0 \pm 1,1$ & $3,5 \pm 1,3$ & 0,072 \\
\hline $\begin{array}{l}\text { 2. Sağlık sorunlarım yüzünden diğer insanların benden çok fazla hoşlanmadıklarını } \\
\text { hissediyorum }\end{array}$ & $1,8 \pm 0,9$ & $1,4 \pm 0,8$ & 0,050 \\
\hline 3. Görünüşümden memnunum & $3,3 \pm 1,5$ & $4,2 \pm 1,2$ & 0,016 \\
\hline 4. Başkalarının yardımına çok intiyacım oluyor & $2,9 \pm 1,3$ & $1,8 \pm 1,0$ & 0,001 \\
\hline 5. İnsanların bana yardım etmek zorunda kalması beni rahatsız ediyor & $2,6 \pm 1,4$ & $1,5 \pm 0,9$ & 0,001 \\
\hline 6. Fizyoterapi yapılması için çok istekliyim & $3,1 \pm 1,3$ & $2,3 \pm 1,6$ & 0,028 \\
\hline 7. Sağlık sorunlarım yüzünden evde sorunlar çıkıyor & $1,5 \pm 0,9$ & $1,5 \pm 1,3$ & 0,340 \\
\hline 8. Diğer çocuklar kadar iyi yürüyemediğim için kızgınım & $2,1 \pm 1,4$ & $1,6 \pm 1,2$ & 0,145 \\
\hline 9. Ağrım oluyor & $1,8 \pm 0,9$ & $1,8 \pm 1,2$ & 0,814 \\
\hline 10. Tekerlekli sandalyem/destek aletlerim yüzünden benimle dalga geçiyorlar & $1,34 \pm 0,7$ & $1,21 \pm 0,9$ & 0,078 \\
\hline $\begin{array}{l}\text { 11. Sağlık sorunlarım yüzünden bana kız ya da erkek kardeşlerimden daha farklı } \\
\text { muamele gösterildiğini düşünüyorum }\end{array}$ & $1,4 \pm 0,9$ & $1,6 \pm 1,1$ & 0,427 \\
\hline 12. Sağlık sorunlarımdan utanıyorum & $1,6 \pm 0,9$ & $1,2 \pm 0,6$ & 0,030 \\
\hline 13. Sağlık sorunlarım nedeniyle ailem bazı şeyleri yapmamı yasakladı & $1,9 \pm 1,1$ & $1,7 \pm 1,2$ & 0,241 \\
\hline 14. Ailemin benden çok fazla şey beklediğini düşünüyorum & $1,8 \pm 1,2$ & $2,0 \pm 1,4$ & 0,725 \\
\hline 15. Sağlık sorunlarım nedeniyle kendimden memnun değilim & $2,3 \pm 1,2$ & $1,6 \pm 1,3$ & 0,012 \\
\hline 16. Ailem bana hasta olduğum için özellikle iyi davranıyor & $2,9 \pm 1,6$ & $2,7 \pm 1,8$ & 0,724 \\
\hline 17.Insanlar bir şeyler yaparken sağlık sorunlarımdan dolayı beni dışlıyorlar & $1,5 \pm 0,9$ & $1,5 \pm 1,0$ & 0,685 \\
\hline 18. Gelecekte sağlık sorunlarım nedeniyle bir iş sahibi olamamaktan korkuyorum & $2,0 \pm 1,3$ & $1,4 \pm 0,9$ & 0,020 \\
\hline $\begin{array}{l}\text { 19. Sağlık sorunlarımın karşı cinsten bir arkadaşımın(sevgilimin) olmasını } \\
\text { engelleyebileceğini düşünüyorum }\end{array}$ & $1,8 \pm 1,0$ & $1,7 \pm 1,2$ & 0,461 \\
\hline 20. Sağlık sorunlarım nedeniyle diğer insanlara bağımlı olduğumu hissediyorum & $2,4 \pm 1,5$ & $1,5 \pm 0,7$ & 0,020 \\
\hline 21. Duygularımı ailemden saklıyorum & $1,9 \pm 1,2$ & $2,0 \pm 1,2$ & 0,680 \\
\hline 22. Sağlık sorunlarım nedeniyle evdeki pek çok karar bana danışılarak verilir & $2,1 \pm 1,4$ & $2,1 \pm 1,4$ & 0,984 \\
\hline 23. Sağlık sorunları olmayan diğer çocukların yaptıkları şeyleri ben de yapabilirim & $3,3 \pm 1,2$ & $3,6 \pm 1,3$ & 0,217 \\
\hline 24. Sağlık sorunlarım nedeniyle okulda derslere dikkatimi veremiyorum & $2,2 \pm 1,2$ & $1,7 \pm 1,3$ & 0,029 \\
\hline 25. Sürekli ilaç almak zorunda olmak beni sıkıyor & $3,2 \pm 1,3$ & $2,3 \pm 1,6$ & 0,012 \\
\hline 26. Aldığım ilaçlardan dolayı kendimi hasta gibi hissediyorum & $2,3 \pm 1,2$ & $2,0 \pm 1,5$ & 0,106 \\
\hline 27. Zaman zaman ilaçlarımı alamıyorum & $2,3 \pm 1,0$ & $1,8 \pm 1,0$ & 0,070 \\
\hline 28. Tekerlekli sandalyem/destek aletlerim beni sinir ediyor & $2,3 \pm 1,1$ & $1,5 \pm 1,1$ & 0,002 \\
\hline 29. Benzer sorunları olan diğer çocuklarla daha sık görüşmek isterim & $3,0 \pm 1,2$ & $2,8 \pm 1,4$ & 0,629 \\
\hline Toplam & $2,3 \pm 0,5$ & $2,0 \pm 0,6$ & 0,012 \\
\hline
\end{tabular}

\section{Tartışma}

Sağııkla ilgili yaşam kalitesi bir hastalığın ya da tedavisinin hastada yarattığı etkinin algılanışı olarak tanımlanmaktadır. Yaşam kalitesi değerlendirilirken, bireye kendi yaşamı ile ilgili ne hissettiği sorulmakta ve bireyi tüm özellikleriyle bir bütün olarak ele alarak bireyin fiziksel, ruhsal ve sosyal iyilik halini derecelendirmek amaçlanmaktadır [7]. Modern tedavi yöntemleri ile 1990'lı yıllardan sonra sağkalım oranlarının giderek arttığı spina bifida'lı hastalarda günümüzde yaşam kalitesinin iyileştirilmesine yönelik uygulamalar güncel hale gelmiştir [1, 4].
Sağlıklı bireyler ile yapılan karşılaştırmalarda spina bifida'lı hastaların genel olarak hayat kalitesindeki düşüklük birçok çalışma ile ortaya konulmuştur [4]. Günlük hayatı sınırlayan başlıca klinik problemler nörolojik sekelin şiddetine göre ortaya çıkan lökomotor işlevsel yetersizlikler ile mesane ve bağırsak işlevlerindeki bozukluklardır $[1,4]$. Bizim çalışmamızda 13 yaşından küçük spina bifida'lı çocuklarda inkontinansın yaşam kalitesi üzerine etkisi bulunamadı. Buna karşılık ergenlik döneminde üriner inkontinansın ve TAK uygulamasının hastaların yaşam kalitesi üzerine kötüleştirici bir etkisi olduğunu saptadık. 
Rendeli ve ark.'ı [8] 29 spina bifida hastasını değerlendirdiklerinde kontinans sorunlarının yaşam kalitesinin etkileyen en önemli faktör olduğunu gösterdiler. Canaz ve ark.'ı [9] kontinans sorunlarının ve TAK kullanımının yaşam kalitesini anlamlı şekilde düşürdüğünü saptadılar. Bununla birlikte Zegers ve ark.'ı da [10] spina bifidalı çocuklarda genel yaşam kalitesinde sağlıklı kontrollere göre daha düşük skorlar göstermekle birlikte; mobilite, lezyonun şiddeti, hidrosefali ve TAK uygulamasının yaşam kalitesi üzerine etkilerini gösteremediler. Diğer bazı çalışmalarda da inkotinansın yaşam kalitesi üzerindeki kötüleştirici etkisi olmadığı sonucuna varılmıştır [11, 12]. Bu çelişkili sonuçlar farklı nedenlere bağlı olabilir. Araştırma yapılan grupta ağır çoklu sistem yakınmaları fazla olan hastaların olması tekil değerlendirmelerin ölçümlenmesini zorlaştırabilir. Bununla birlikte hastaların sorunlarını içselleştirip iyi adaptasyon göstermesi ya da tam tersine hastalığı hafif olan çocukların kendilerini sağlıklı bireyler ile karşılaştırıp aşırı direnç geliştirmeleri yaşam kalitesi sonuçları arasında farklılıklara neden olabilir.

Bir diğer farklı sonuç nedeni de bizim çalışmamızda olduğu gibi farklı yaş gruplarındaki hastaların aynı duruma karşı geliştirdikleri yanıtlar arasındaki fark olabilir. Szymanski ve ark.'ı [13] yaşam kalitesi üzerine inkontinansın 8-9 yaşlarındaki hastalarda olumsuz bir etkisi yokken 10 yaşından itibaren yaşam kalitesini azalttığı ve bu etkinin 14 yaşından sonra daha belirgin hale geldiğini gösterdiler. Gerçekten bizim çalışmamızda da 12 yaş altında saptayamadığımız inkontinans ve TAK uygulamasına bağlı hayat kalitesindeki azalmanın ergen hastalarda aşikar hale geldiğini saptadık. Özellikle bedensel ve duygusal iyilik hali ile özsaygı alt boyutlarında TAK kullanımına bağlı anlamlı etkilenme olduğu gösterildi. Bu sonucun açıklaması ergenlik çağına özgü nedenler ile ilişkili olabilir. Küçük yaşlarda çocuklar, kendi dar çevreleri ile algıladıkları sosyal hayatı yaşarken inkontinansın yaşam kalitesi üzerine etkisi karşılaştırabilir ölçüde olmayabilir. Öte yandan büyüyüp sosyal hayatın içine giren çocuklarda hem inkontinansın kendisi hem de TAK kullanımı dışa dönük güncel hayatta büyük bir sıkıntıya dönüşebilir. Böylece artan sosyal hayat ile birlikte yaşa özgün emosyonel faktörlerin bu hasta grubunda inkontinans ve TAK uygulamasına bağlı hayat kalitesinde kötüleşmeyi belirginleştirebileceğini düşünüyoruz.

Spina bifida'lı çocuklarda inkontinans ve TAK uygulamasının yaşam kalitesi üzerine etkisinin gösterilmesindeki önemli bir diğer zorluk genel yaşam kalitesi ölçeklerinin yetersizliklerinden kaynaklanmaktadır. İnkontinans sorgulamasının yapılmadığı ölçeklerden objektif sonuçlar beklemek zordur. Son yıllarda mesane ve barsak fonksiyon bozukluğuna odaklanan kapsamlı bir alan dahil olmak üzere spina bifidaya özgü ölçekler geliştirilmeye başlanmıştır $[14,15]$. Bizim çalışmamızda hastaların \%80'i inkontinans nedeni ile TAK yapıyordu. Bu durum TAK uygulamasının spina bifida'lı hastaların yaşamlarında önemli bir yeri olduğunu göstermektedir. KINDL-R spina bifida modülü uygulandığında inkontinans nedeni ile TAK yapan hastalarımızın yaşam kalitesinin belirgin şekilde düşük olduğu gösterilmiştir. Gerçekten spina bifida'lı hasta gruplarında hastalığa özgü değişkenlerin yaşam kalitesi üzerine etkisinin ölçülmesinde bu tür özgün ölçekler daha objektif sonuçlar verebilir.

$\mathrm{Bu}$ çalışmanın birtakım kısıtılıkları da mevcuttur. Hem olgu sayısı hem de kesitsel doğası bazı ölçeklerde yetersiz sonuçlara neden olmuş olabilir. Temiz aralıklı kateterizasyon yapmayan hasta sayısının azlığı da karşılaştırmalarda istatistiksel anlamlılığı azaltmış olabilir. Ayrıca uyguladığımız yaşam ölçeğinin spina bifida modülünün Türkçe versiyonunun henüz büyük serilerde doğrulamasının yapılmamış olması da sonuçlarımız üzerinde kısıtlılık yaratabilir.

Sonuç olarak, spina bifida'ı çocuklarda özellikle sosyal hayata daha fazla girilmeye başlanan ergenlik döneminde inkontinans ve bunu önlemek için yapılan TAK uygulamaları yaşam kalitesini ciddi olarak azaltmaktadır. Bu hastalarınyaşamkalitesininölçeklendirilmesinde hastalığa özgü modüllerin kullanılması objektif bulgulara ulaşılmasını sağlayacaktır. Daha kesin sonuçlara ulaşılması için büyük serilerde kontrollü çalışmaların yapılması bu sonuçların geçerliliğini güçlendirecektir.

Çıkar ilişkisi: Yazarlar çıkar ilişkisi olmadığını beyan eder. 


\section{Kaynaklar}

1. Copp AJ, Adzick NS, Chitty LS, Fletcher JM, Holmbeck GN, Shaw GM. Spina bifida. Nat Rev Dis Primers 2015;30:15007. https://doi.org/10.1038/nrdp.2015.7

2. Botto LD, Moore CA, Khoury MJ, Erickson JD. Neuraltube defects. N Engl J Med 1999;341:1509-1519. https://doi.org/10.1056/NEJM199911113412006

3. Phillips LA, Burton JM, Evans SH. Spina bifida management. Curr Probl Pediatr Adolesc Health Care 2017;47:173-177. https://doi.org/10.1016/j. cppeds.2017.06.007

4. Sawin KJ, Bellin MH. Quality of life in individuals with spina bifida: a research update. Dev Disabil Res Rev 2010;16:47-59. https://doi.org/10.1002/ddrr.96

5. Eser $\mathrm{E}$, Yüksel $\mathrm{H}$, Baydur $\mathrm{H}$, et al. The psychometric properties of the new Turkish generic health-related quality of life questionnaire for children (Kid-KINDL). Turk Psikiyatri Derg 2008;19:409-417

6. Ural Z, Türe İ, Akil İ, Eser E. Spina bifida hastalığının çocuklar ve ailelerin yaşam kalitesi üzerindeki etkisi. Paper presented at: IV. Ulusal Pediatrik Üroloji Kongresi; 23-25 Mayıs 2013; Konya, Türkiye.

7. Üneri Ö, Memik Çakın N. Çocuklarda yaşam kalitesi kavramı ve yaşam kalitesi ölçeklerinin gözden geçirilmesi. Çocuk ve Gençlik Ruh Sağlığı Dergisi 2007;14:48-56

8. Rendeli C, Ausili E, Tabacco F, et al. Assessment of health status in children with spina bifida. Spinal Cord 2005;43:230-235. https://doi.org/10.1038/ sj.sc. 3101707

9. Canaz H, Canaz G, Dogan I, Alatas I. Health-related quality of life in non-paraplegic (ambulatory) children with myelomeningocele. Childs Nerv Syst 2017;33:1997-2002. https://doi.org/10.1007/s00381017-3494-y

10. Zegers SHJ, Houterman S, Uiterwaal CSPM, Winkler Seinstra PLH, Kimpen JLL, de Jong de Vos van Steenwijk CCE. Quality of life in children with spina bifida: a cross-sectional evaluation of 102 patients and their parents. J Child Adolesc Behav 2015:3:225. https://doi.org/10.4172/2375-4494.1000225

11. Freeman KA, Smith $\mathrm{K}$, Adams E, Mizokawa S, Neville Jan A. Is continence status associated with quality of life in young children with spina bifida? J Pediatr Rehabil Med 2013;6:215-223. https://doi.org/10.3233/ PRM-140263

12. Smith K, Neville Jan A, Freeman KA, et al. The effectiveness of bowel and bladder interventions in children with spina bifida. Dev Med Child Neurol 2016;58:979-988. https://doi.org/10.1111/dmcn.13095

13. Szymanski KM, Cain MP, Whittam B, Kaefer M, Rink $\mathrm{RC}$, Misseri R. Incontinence affects health-related quality of life in children and adolescents with spina bifida. J Pediatr Urol 2018;14:279.e1-e8. https://doi. org/10.1016/j.jpurol.2018.02.021
14. Parkin PC, Kirpalani HM, Rosenbaum PL, et al. Development of a health-related quality of life instrument for use in children with spina bifida. Qual Life Res 1997;6:123-132. https://doi. org/10.1023/a:1026486016212

15. Szymański KM, Misseri R, Whittam B, et al. Validation of QUALAS-T, a health-related quality of life instrument for teenagers with spina bifida. Cent European J Urol 2017;70:306-313. https://doi.org/10.5173/ ceju.2017.1195

Teşekkür: Yazarlar KINDL-spina bifida modülünün Türkçe versiyonu ile ilgili katkılarından dolayı Dr. Zeliha Ural Büyükbesnili'ye teşekkür ederler.

Etik kurul onayı: İstanbul Medeniyet Üniversitesi Göztepe Eğitim ve Araştırma Hastanesi Klinik Araştırmalar Etik Kurulu'nun 12.12.2018 tarih ve 2018/0490 sayılı etik kurul onayı gözetilmiştir.

\section{Yazarların makaleye olan katkıları}

C.C. çalışmanın ana fikrini ve hipotezini kurgulamıştır. A.E.A. teoriyi geliştirmiş ve gereç ve yöntem bölümünü düzenlemiştir. Sonuçlar kısmındaki verilerin değerlendirmesini A.E.A ve C.C. yapmışlardır. Makalenin tartışma bölümü A.E.A. tarafından yazılmış, C.C. gözden geçirip gerekli düzeltmeleri yapmış ve onaylamıştır. Ayrıca yazarlar çalışmanın tamamını tartışmış ve son halini onaylamıştır. 